\title{
Nyeri Punggung Bawah Pada Ibu Hamil Trimester II Dan III
}

\author{
Kurniati Devi Purnamasari \\ Fakultas Ilmu Kesehatan, Universitas Galuh, Indonesia \\ e-mail : kurniatidevip@gmail.com \\ (Diterima 19-02-2019; disetujui 25-04-2019; dipublish 09-05-2019)
}

\begin{abstract}
Abstrak
Nyeri Punggung Bawah merupakan keluhan nyeri kompleks yang paling sering terjadi di dunia maupun Indonesia. Nyeri punggung bawah pada ibu hamil trimester II dan III merupakan keluhan umum yang sering terjadi di kalangan ibu hamil, diperkirakan sekitar $70 \%$ wanita hamil mengeluhkan beberapa bentuk nyeri punggung pada suatu saat dalam kehamilan, persalinan hingga postpartum. Penelitian ini dilakukan untuk menggambarkan nyeri punggung bawah pada ibu hamil trimester II dan III. Desain studi deskriptif potong lintang, pengambilan sampel secara konsekutif dilakukan pada bulan juni 2018, dengan menggunakan kuesioner. Subjek penelitian adalah ibu hamil trimester II dan III.Sebanyak 30 responden masuk dalam penelitian, responden yang mengalami nyeri ringan sebanyak 20\%, 50\% mengalami nyeri sedang dan sebanyak 30\% mengalami nyeri berat disertai dengan gejala penyerta. Meski merupakan suatu masalah, 82\% remaja hanya membiarkan saja saat nyeri timbul atau hanya minum air hangat dan menekan bagian yang sakit (18\%). Para ibu hamil trimester II dan III mencari pertolongan kepada suami dan keluarga $(87,2 \%)$ mengenai masalah yang timbul dan hanya, 12,8\% dari ibu hamil trimester II dan III yang mencari pertolongan ke tenaga kesehatan/ bidan. Sebagian besar responden pernah mengalami nyeri otot punggung bawah. Umumnya informasi tentang punggung bawah paling banyak didapatkan dari wanita hamil lainnya dan orangtua.Saat mengalami punggung bawah sebagian besar ibu hamil meminta pertolongan kepada suami dan keluarga.Edukasi kesehatan tentang masalah nyeri punggung bawah penting untuk ibu hamil trimester II dan III, suami dan keluarganya, dan perlunya evaluasi rutin masalah nyeri punggung bawah pada ibu hamil trimester II dan III oleh para klinisi.
\end{abstract}

Kata Kunci: nyeri punggung bawah, ibu hamil trimester II dan III

\begin{abstract}
Low Back Pain is a complaint of complex pain that occurs most frequently in the world and Indonesia. Lower back pain in pregnant women of the second and third trimester is a common complaint that often occurs among pregnant women, it is estimated that about $70 \%$ of pregnant women complain of some form of back pain at some time in pregnancy, labor until postpartum. This study was conducted to describe lower back pain in pregnant women in the third trimester. A cross-sectional descriptive study design, consecutive sampling was conducted in June 2018, using a questionnaire. Research subjects were pregnant women in the second and third trimester. There are 30 respondents entered the study, respondents who experienced mild pain as much as 20\%, 50\% experienced moderate pain and as much as $30 \%$ experienced severe pain accompanied by accompanying symptoms. Although it is a problem, $82 \%$ of teenagers just leave it when pain arises or just drink warm water and suppress the affected part (18\%). In the second and third trimester pregnant women seek help from their husbands and families (87.2\%) regarding problems that arise and only $12.8 \%$ of the second and third trimester pregnant women seek help from health workers /midwives. Most respondents have experienced lower back muscle pain. Generally, the information about the lower back is mostly obtained from other pregnant women and parents. When experiencing a lower back most pregnant women ask for help to their husbands and families. Health education about the problem of low back pain is important for the second and third-trimester pregnant mother, husband and family, and the need for routine evaluation of low back pain problems in the second and third-trimester pregnant mothers by clinicians.
\end{abstract}

Keywords: low back pain, second and third-trimester pregnant women 


\section{PENDAHULUAN}

Kehamilan adalah periode unik dalam kehidupan yang terkait dengan perubahan hormonal dan fisiologis lainnya pada seorang wanita hamil, yang dapat memicu atau mengubah jalannya gangguan neurologis dan kejiwaan. Selain itu, banyak prosedur diagnostik yang dapat dilakukan pada wanita normal tidak hamil yang dilarang selama kehamilan untuk alasan kesehatan ibu hamil. Keputusan terapeutik dan manajemen pasien hamil dengan keluhan nyeri sangat tergantung pada masalah keseimbangan yang wajar terjadi selama kehamilan, yang dikaitkan antara risiko yang terjadi tanpa adanya pengobatan versus pengobatan aktif untuk ibu dan janinnya ${ }^{1}$.Berbagai masalah yang timbul pada kehamilan trimester II dan III merupakan masalah psikologis yang sering dikeluhkan pada ibu hamil, seperti kecemasan dan nyeri ${ }^{2}$, Di antara keluhan tersebut, nyeri punggung bawah yang paling umum dilaporkan, terjadi pada 60\%-90\% ibu hamil, dan merupakan salah satu penyebab angka kejadian persalinan sesar. $^{3}$

Nyeri merupakan masalah yang sangat sering terjadi pada kehamilan khususnya pada trimester II dan III kehamilan. Fenomena nyeri saat ini telah menjadi masalah kompleks yang didefinisikan oleh International Society for The Study of Pain sebagai "pengalaman sensorik dan emosi yang tidak menyenangkan akibat kerusakan jaringan, baik aktual maupun potensial".Nyeri menyebabkan ketakutan dan kecemasan sehingga dapat meningkatkan stres dan perubahan fisiologis yang drastis selama kehamilan. Nyeri dan kecemasan bekerja secara sinergis ${ }^{3}$, yang saling memperburuk satu sama lain $^{4,5}$. Fenomena nyeri pada bagian punggung ibu hamil adalah salah satu keluhan yang paling sering dilaporkan di kalangan ibu hamil, bervariasi dari $50 \%$ sampai $80 \%$, berdasarkan pada penelitian di berbagai negara sebelumnya ${ }^{6}$, bahkan $8 \%$ diantaranya mengakibatkan kecacatan berat ${ }^{7}$.

Saat ini hanya ada sedikit bukti empiris yang menunjukkan bahwa hal ini telah berdampak di bidang perawatan individu yang menderita nyeri, nyeri akut yang ditangani dengan buruk meningkatkan risiko rasa sakit terus-menerus, mengurangi kualitas hidup dan meningkatkan penggunaan layanan kesehatan yang bersifat kuratif $^{8}$.Meskipun angka kejadiannya cukup tinggi, masih sedikit para ibu hamil yang mencari informasi mengenai masalah yang timbul pada nyeri punggung bawah selama kehamilan dan dampaknya.Tersedianya informasi mengenai nyeri selama kehamilan dan permasalahannya, khususnya nyeri punggung bawah pada trimester trimester II dan III III merupakan hal yang penting untuk perkembangan pelayanan kesehatan bagi ibu hamil.Tujuan penelitian untuk mengetahui gambaran nyeri punggung bawah pada ibu hamil trimester trimester II dan III III.

\section{METODE PENELITIAN}

Teknik sampling dalam penelitian ini adalah non probability sampling jenis consecutive sampling, yaitu semua subjek yang datang ke Puskesmas Ngesrep secara berurutan dan memenuhi kriteria dimasukkan dalam penelitian sampai jumlah subjek yang diperlukan terpenuhi. Penelitian ini dilakukan di Puskesmas Ngesrep menggunakan desain studi deskriptif dengan metode potong lintang, pada bulan juni 2018. Subjek penelitian adalah Ibu hamil trimester II dan III yang melakukan kunjungan Antenatal Care (ANC) di Puskesmas Ngesrep.

Kuesioner penelitian menggunakan kuesioner Visual Analog Scale (VAS) dan kuesioner yang terdiri dari 3 pertanyaan seputar nyeri punggung yang dialami ibu. Berdasarkan berat ringannya gejala nyeri, nyeri punggung bawah dikelompokkan menjadi derajat ringan bila nyeri ringan yang tidak mengganggu aktivitas sehari-hari ibu (skala 1-3), derajat sedang bila nyeri sedang yang bisa mengganggu aktivitas sehari-hari tetapi masih bisa beraktivitas normal (skala 47), sedangkan derajat berat bila nyeri hebat dan ibu tidak dapat melakukan kegiatannya dan hanya bisa tirah baring (skala 8-10). ${ }^{9}$ Skala Visual Analog Scale (VAS) yang digunakan dalam penelitian ini ditunjukkan oleh gambar 1 . 


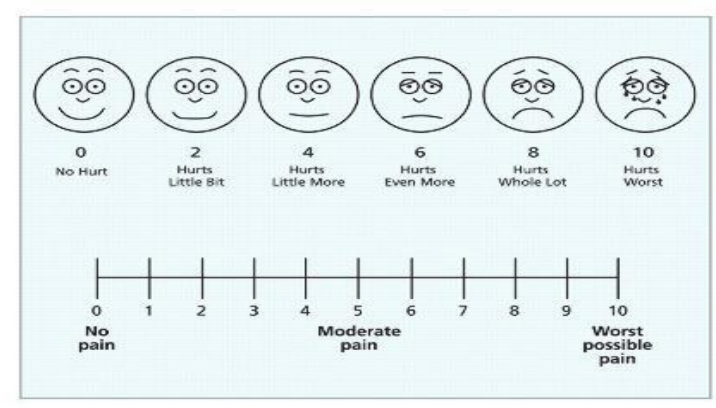

Gambar 1.Visual Analog Scale (VAS) ${ }^{10}$

Sebelum pengisian kuesioner, responden diberikan penjelasan dan dimintakan persetujuan responden untuk mengikuti penelitian.Data dianalisis dengan program komputerisasi.Adanya nyeri hebat menyebabkan reaksi reflekstorik pada otot-otot lumbo dorsal terutama otot erector spine pada L4 dan L5 sehingga terjadi peningkatan tonus yang terlokalisir (spasme) sebagai "guarding" (penjagaan) terhadap adanya gerakan. Jika spasme otot berlangsung lama maka otot akan cenderung menjadi tightness. Keadaan tightness pada otot-otot erector spine akan memperberat nyeri karena terjadi ischemic dan menyebabkan alignment spine menjadi abnormal sehingga menimbulkan beban stres/kompresi yang besar pada diskus intervertebralis yang cidera ${ }^{11}$.

Adanya kerusakan menyebabkan terlepasnya zat-zat iritan seperti prostaglandin, bradikinin, dan histamin sehingga merangsang serabut saraf $\mathrm{A} \delta$ dan tipe $\mathrm{C}$ (bermylein tipis). Impuls tersebut dibawa ke ganglion dorsalis dan masuk kedalam medulla spinalis melalui cornu dorsalis, yang kemudian dibawa ke level Sistem Saraf Pusat yang lebih tinggi melalui traktus spinothalamicus dan spinoreticularis. Adanya rangsangan pada ganglion dorsalis akan memicu produksi "P" substance. Produksi "P"substance akan merangsang terjadinya reaksi inflamasi.

\section{HASIL PENELITIAN}

Karakteristik dalam penelitian ini terdiri dari usia ibu, paritas, umur kehamilan, Tinggi Fundus Uteri (TFU), Tinggi Badan (TB), Berat Badan (BB), Skala Visual Analog Scale (VAS) nyeri punggung bawah.

Tabel 1. Karakteristik responden

\begin{tabular}{llll}
\hline arakteristik & in & ax & an \pm SD \\
\hline bu (tahun) & 1 & 0 & $73 \pm 2.71$ \\
\hline re- & & $!$ & $3 \pm 0.52$ \\
\hline $\begin{array}{l}\text { ehamilan } \\
(\text { minggu) }\end{array}$ & 3 & 8 & $26 \pm 7.40$ \\
\hline m) & 2 & 0 & $93 \pm 7.03$ \\
\hline$)$ & 2 & $i 7$ & $.46 \pm 4.25$ \\
\hline AS & ) & 0 & $i 6 \pm 14.69$ \\
\hline
\end{tabular}

Berdasarkan tabel 1 dapat dilihat dari sebanyak 30 orang subjek yang diteliti bahwa karakteristik umur ibu nilai rata-ratanya adalah (24.73 \pm 2.71$)$ tahun dengan rentang umur responden adalah 21- 30 tahun.Paritas rata-rata responden adalah $(1.53 \pm 0.52)$ dengan rentang kehamilan 1-2.Rata-rata umur kehamilan responden adalah $(27.26 \pm 7.40)$ minggu dengan rentang umur kehamilan 13- 38 minggu.Rata-rata TFU responden adalah $(23.93 \pm 7.03) \mathrm{cm}$ dengan rentang $12-30 \mathrm{~cm}$. Rata-rata tinggi badan responden adalah $(156.46 \pm 4.25) \mathrm{cm}$ dengan rentang $152-167 \mathrm{~cm}$. Rata -rata berat badan responden adalah $(62.36 \pm 14.69) \mathrm{kg}$ dengan rentang berat badan 40-80 kg.Rata-rata Indeks Massa Tubuh (IMT) responden adalah (25.45 \pm 5.72) dengan rentang Indek Massa Tubuh (IMT).Rata-rata skala nyeri Visual Analog Scale (VAS) responden adalah $(6.33 \pm 1.63)$ dengan rentang skala nyeri 5-10.

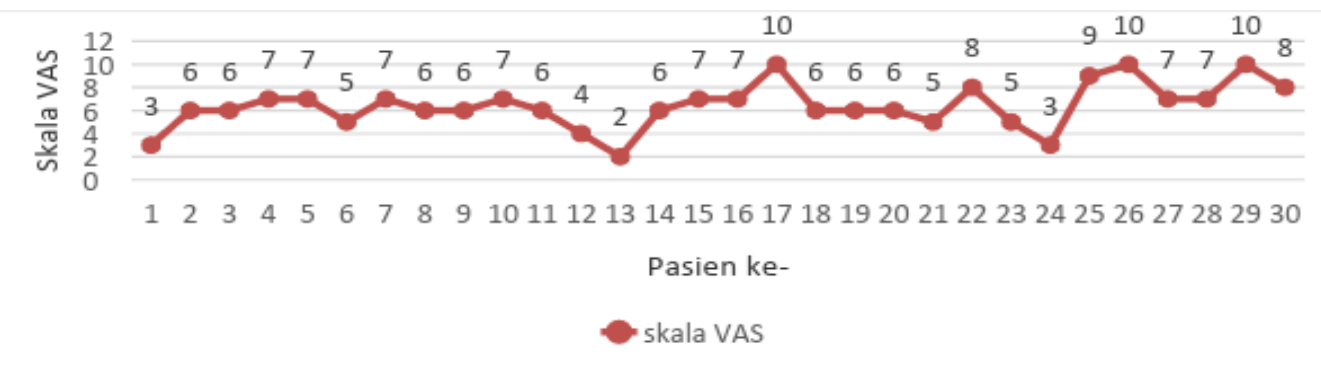

Gambar 2.Tren skala VAS pada nyeri otot punggung bawah 
Gambaran pengukuran nyeri punggung bawah menggunakan Visual Analog Scale (VAS) ini ditunjukkan dengan tabel Gambar 3. Berdasarkan Gambar 3 menunjukkan bahwa nyeri punggung bawah yang dialami oleh responden ibu hamil trimester III sebanyak 3 $(10 \%)$ orang dengan skala nyeri VAS ringan, sebanyak 22 orang $(73,33 \%)$ dengan skala nyeri VAS sedang dan skala nyeri VAS berat sebanyak 5 orang $(16,67 \%)$. Sebanyak 30 kuesioner diberikan kepada responden dan responden bersedia mengisi kuesioner.Didapatkan 30 (100\%) responden pernah mengalami nyeri punggung bawah selama kehamilan.

Tabel 2.Distribusi responden nyeri punggung bawah berdasarkan derajat nyeri, lama nyeri, gejala penyerta, dan tempat mencari pertolongan

\begin{tabular}{|c|c|c|c|c|c|}
\hline \multirow[t]{2}{*}{ Variabel } & \multirow[t]{2}{*}{$(\mathbf{n}=30)$} & \multicolumn{4}{|c|}{ Tempat mencari pertolongan } \\
\hline & & suami & keluarga & bidan & $\begin{array}{l}\text { Lain- } \\
\text { lain }\end{array}$ \\
\hline \multicolumn{6}{|l|}{ Derajat nyeri } \\
\hline Ringan & $3(10 \%)$ & $1(33,33 \%)$ & $2(66,67 \%)$ & 0 & 0 \\
\hline Sedang & $22(73,33 \%)$ & $20(90,90 \%)$ & $2(9,10 \%)$ & 0 & 0 \\
\hline \multicolumn{6}{|l|}{ Lama nyeri } \\
\hline$<24$ jam & $26(86,66 \%)$ & $21(80,76 \%)$ & $4(15,38 \%)$ & $1(3,86 \%)$ & 0 \\
\hline 1 hari & $2(6,67 \%)$ & $2(100 \%)$ & 0 & 0 & 0 \\
\hline Beberapa hari & $2(6,67 \%)$ & 0 & 0() & $2(100 \%)$ & 0 \\
\hline \multicolumn{6}{|c|}{ Gejala penyerta } \\
\hline Tanpa gejala & $28(93,33 \%)$ & $20(71,42 \%)$ & $7(28,58 \%)$ & 0() & 0 \\
\hline Ada gejala & $2(6,67 \%)$ & 0 & 0 & $2(100 \%)$ & 0 \\
\hline \multicolumn{6}{|c|}{$\begin{array}{ll}\text { Berdasarkan tabel 1 di atas dapat dilihat } & \text { yang mengalami nyeri punggung bawah } \\
\text { va pada ibu hamil yang mengalami nyeri } & \text { dengan nyeri berat paling banyak meminta } \\
\text { ggung bawah, sebagian besar }(73,33 \%) & \text { pertolongan kepada teman suami (40\%) bukan } \\
\text { galami nyeri sedang, sedangkan yang } & \text { kepada bidan. } \\
\text { galami nyeri ringan dan berat } 10 \% \text { dan } & \text { Berdasarkan hasil penelitian diperoleh } \\
7 \% \text {. Dijumpai } 26 \text { orang }(86,66 \%) & \text { hasil bahwa meski nyeri punggung bawah pada } \\
\text { onden mengalami nyeri punggung bawah } & \text { ibu hamil trimester III merupakan suatu } \\
\text { ng dari } 24 \text { jam, 6,67\% mengalami nyeri } & \text { masalah yang dapat menimbulkan nyeri dari } \\
\text { angsung selama satu hari, dan } 6,67 \% & \text { ringan sampai berat, namun seperti yang } \\
\text { pai beberapa hari. Sebanyak hampir } & \text { tampak pada Tabel 2 para responden lebih } \\
\text { luruhan ibu hamil dengan persentase } & \text { memilih minum air hangat/ memijat area } \\
3 \text { \% responden mengalami dismenorea } & \text { punggung bawah saat terjadi nyeri (70\%), atau } \\
\text { disertai gejala penyerta dan 6,67\% } & \text { dibiarkan saja karena nyeri akan hilang dengan } \\
\text { rtai gejala penyerta. Gejala penyerta yang } & \text { sendirinya (16,66\%). Responden yang lain } \\
\text { orkan yaitu mual muntah (50\%) dan } & (6,67 \%) \text { memilih menggunakan analgetik, } \\
\text { nderungan mudah marah atau gangguan } & \text { seperti parasetamol atau obat-obatan yang } \\
\text { si (50. Pada Tabel 1 tertera bahwa pada } & \text { dapat menghilangkan rasa nyeri haid, dan } \\
\text { i sedang paling banyak meminta } & (6,67 \%) \text { lainnya yang melakukan pemeriksaan } \\
\text { olongan pada suami (90,90\%). responden } & \text { ke bidan. }\end{array}$} \\
\hline
\end{tabular}


Tabel 3.Distribusi responden berdasarkan cara mengurangi rasa nyeri saat mengalami nyeri punggung bawah

\begin{tabular}{|l|c|c|}
\hline Variabel & $\begin{array}{l}\text { Jumlah } \\
(\mathbf{n = 3 0})\end{array}$ & Persentase \\
\hline Analgetik & 2 & 6,67 \\
\hline $\begin{array}{l}\text { Minum air } \\
\text { hangat/dipijat }\end{array}$ & 21 & 70 \\
\hline $\begin{array}{l}\text { Periksa ke } \\
\text { bidan }\end{array}$ & 2 & 6,67 \\
\hline Dibiarkan saja & 5 & 16,66 \\
\hline
\end{tabular}

Tabel 4.Distribusi responden berdasarkan sumber informasi

\begin{tabular}{|l|c|c|}
\hline Variabel & $\begin{array}{c}\text { Jumlah } \\
(\mathbf{n = 3 0})\end{array}$ & Persentase \\
\hline Suami & 2 & 6,67 \\
\hline Keluarga & 21 & 70 \\
\hline Bidan & 6 & 20 \\
\hline Lain-lain & 1 & 3,33 \\
\hline
\end{tabular}

Sebagian besar ibu hamil lebih menyukai mencari informasi tentang nyeri punggung bawah pada keluarga (70\%) dan bidan $(23,33 \%)$ dibandingkan dengan informasi dari suami $(6,67 \%)$. Mereka juga mencari informasi dari sumber-sumber lain seperti majalah, koran, ataupun internet $(3,33 \%)$ (Tabel 3).

\section{PEMBAHASAN}

Nyeri biasanya memuncak pada usia gestasi 36 minggu dan akan menurun kemudian. Biasanya secara substansial membaik 3 bulan pasca persalinan. ${ }^{12}$ Nyeri punggung yang terus-menerus dapat terjadi pada wanita dengan nyeri pinggang belakang dan panggul belakang, nyeri punggung pada awal kehamilan, kelemahan otot ekstensor belakang, individu yang lebih tua, dan orangorang yang memiliki ketidakpuasan kerja ${ }^{11}$. Sepanjang kehamilan, wanita mengalami perubahan fisiologis yang disebabkan oleh kebutuhan anatomis dan fungsional. ${ }^{6}$ Perubahan higienis mempengaruhi sistem muskuloskeletal dan biasanya menimbulkan rasa sakit, termasuk sakit punggung bawah ${ }^{3}$.

Berdasarkan penelitian yang kami lakukan didapatkan bahwa dari sejumlah 30 orang responden sebagian besar $(73,33 \%)$ mengalami nyeri sedang, sedangkan yang mengalami nyeri ringan dan berat $10 \%$ dan $16,67 \%$.Nyeri punggung bawah adalah penyebab paling sering kecacatan jangka panjang di seluruh dunia ${ }^{13}$ dengan prevalensi sebanyak 6 dari 10 orang ibu hamil di dunia mengalami nyeri punggung bawah selama kehamilannya. ${ }^{14,}{ }^{15}$ Selama kehamilan, relaksasi sendi di bagian sekitar panggul dan punggung bawah ibu hamil kemungkinan terjadi akibat perubahan hormonal.Sejalan dengan bertambahnya berat badan secara bertahap selama kehamilan dan redistribusi pemusatan terdapat pengaruh hormonal pada struktur otot yang terjadi selama kehamilan.Kedua faktor ini mengakibatkan adanya perubahan postur tubuh pada ibu hamil. Perubahan sistem muskuloskeletal terjadi pada saat umur kehamilan semakin bertambahnya kehamilan ${ }^{16}$. Adaptasi muskuloskeletal ini mencakup: peningkatan berat badan, bergesernya pusat berat tubuh akibat pembesaran rahim, relaksasi dan mobilitas. Semakin besar kemungkinan instabilitas sendi sakroiliaka dan peningkatan lordosis lumbal, yang menyebabkan rasa sakit. ${ }^{17}$

Hal ini mengindikasikan adanya kecenderungan bagi otot untuk memendek jika otot abdomen meregang sehingga dapat menyebabkan ketidakseimbangan otot disekitar panggul dan punggung bawah, dan tegangan tambahan dapat dirasakan di atas ligamen tersebut. Akibatnya nyeri punggung yang biasanya berasal dari sakroiliaka atau lumbar, dan dapat menjadi gangguan punggung jangka panjang jika keseimbangan otot dan stabilitas pelvis tidak dipulihkan setelah melahirkan dan postpartum.

Diperkirakan bahwa sekitar 50\% wanita hamil mengeluhkan beberapa jenis nyeri punggung di beberapa titik kehamilan atau selama periode postpartum $^{15}$.

Pada studi hanya sedikit para ibu hamil mencari pertolongan medis saat nyeri punggung bawah timbul.Sebagian besar ibu hamil trimester II dan III yang mengalami nyeri punggung bawah, hanya $23(13,33 \%)$ yang melakukan konsultasi pada bidan dan tenaga kesehatan mengenai masalah yang dialaminya. Didapatkan sebagian besar ibu hamil mengetahui mengenai fisiologis nyeri punggung bawah berdasarkan informasi dari keluarga dan suami sedangkan informasi dari dokter hanya sebesar 3,5\%. Dalam studi lainnya ditemukan bahwa pada wanita hamil di trimester II dan III nyeri punggung bawah lebih banyak terjadi dengan prevalensi sebanyak $(43,24 \%)^{18}$. Penelitian sebelumnya juga menemukan bahwa prevalensi nyeri punggung bawah lebih tinggi pada wanita 
hamil dari trimester ketiga, dengan dari sebagian besar responden lebih memilih minum air hangat/ memijat area punggung bawah saat terjadi nyeri. Hal ini sejalan dengan hasil penelitian yang telah peneliti lakukan.

\section{KESIMPULAN DAN SARAN}

Studi ini menunjukkan bahwa nyeri punggung bawah pada ibu hamil trimester II dan III terjadi dengan prevalensi terbanyak pada skala nyeri sedang. Peningkatan usia kehamilan dan temuan ini empa-ukuran asal biomekanik nyeri pinggang pada wanita hamil.Nyeri punggung bawah sering ditemukan pada kehamilan.Hal ini dapat menjadi indikasi pentingnya edukasi kesehatan tentang nyeri punggung bawah untuk ibu hamil selama trimester II dan III dan suami serta keluarganya, dan evaluasi rutin masalah nyeri punggung bawah oleh para klinisi.Berdasarkan hasil yang diberikan oleh studi ini mengenai nyeri punggung bawah selama kehamilan, penelitian selanjutnya disarankan untuk pemberian intervensi dalam penanganan nyeri punggung bawah pada ibu hamil trimester II dan III.

\section{DAFTAR PUSTAKA}

1. Elsevier. Neurological Disorders and Pregnancy 1st Edition. 8th December 2010 ed: Elsevier; 2011.

2. Hartvigsen J, Hancock MJ, Kongsted A, Louw Q, Ferreira ML, Genevay S, et al. What low back pain is and why we need to pay attention. The Lancet. 2018;391(10137):2356-67.

3. Carvalho MECC, Lima LC, Terceiro CAdL, Pinto DRL, Silva MN, Cozer GA, et al. Low back pain during pregnancy. Revista brasileira de anestesiologia. 2017;67(3):266-70.

4. Durand G, Plata EM. The effects of psychopathic traits on fear of pain, anxiety, and stress. Personality and Individual Differences. 2017;119:198203.
5. Burns SA, Cleland JA, Rivett DA, Snodgrass SJ. Effectiveness of physical therapy interventions for low back pain targeting the low back only or low back plus hips: a randomized controlled trial protocol. Brazilian Journal of Physical Therapy. 2018.

6. Yan C-F, Hung Y-C, Gau M-L, Lin KC. Effects of a stability ball exercise programme on low back pain and daily life interference during pregnancy. Midwifery. 2014;30(4):412-9.

7. Lee D. Chapter 17 - Highlights from an Integrated Approach to the Treatment of Pelvic Pain and Dysfunction A2 Magee, David J. In: Zachazewski JE, Quillen WS, Manske RC, editors. Pathology and Intervention in Musculoskeletal Rehabilitation (Second Edition): W.B. Saunders; 2016. p. 61250.

8. Nickel BT, Klement MR, Byrd WA, Attarian DE, Seyler TM, Wellman SS. Battling the Opioid Epidemic with Prospective Pain Threshold Measurement. The Journal of Arthroplasty. 2018.

9. Rausch M, Zehetleitner M. A comparison between a visual analogue scale and a four point scale as measures of conscious experience of motion. Consciousness and Cognition. 2014;28:126-40.

10. Myles PS, Myles DB, Galagher W, Boyd D, Chew C, MacDonald N, et al. Measuring acute postoperative pain using the visual analog scale: the minimal clinically important difference and patient acceptable symptom state. British Journal of Anaesthesia. 2017;118(3):424-9.

11. Golob AL, Wipf JE. Low Back Pain. Medical Clinics of North America. 2014;98(3):405-28. 
12. Unalmis Erdogan S, Yanikkerem E, Goker A. Effects of low back massage on perceived birth pain and satisfaction. Complementary Therapies in Clinical Practice. 2017;28:169-75.

13. Lima M, Ferreira AS, Reis FJJ, Paes V, Meziat-Filho N. Chronic low back pain and back muscle activity during functional tasks. Gait \& Posture. 2018;61:250-6.

14. Close C, Sinclair M, Liddle D, Mc Cullough J, Hughes C. Women's experience of low back and/or pelvic pain (LBPP) during pregnancy. Midwifery. 2016;37:1-8.

15. Brown A, Johnston R. Maternal experience of musculoskeletal pain during pregnancy and birth outcomes: Significance of lower back and pelvic pain. Midwifery. 2013;29(12):1346-51.
16. Darwich AA, Diwan SA. Management of back pain in pregnancy. Techniques in Regional Anesthesia and Pain Management. 2009;13(4):251-4.

17. Carvalho MECC, Lima LC, Terceiro CAdL, Pinto DRL, Silva MN, Cozer GA, et al. Low back pain during pregnancy. Brazilian Journal of Anesthesiology (English Edition). 2017;67(3):266-70.

18. Katonis $\mathrm{P}$, Kampouroglou A, Aggelopoulos A, Kakavelakis K, Lykoudis S, Makrigiannakis A, et al. Pregnancy-related low back pain. Hippokratia. 2011;15(3):205. 